\title{
Eros y Tanatos en el Poema XXX de Trilce
}

\author{
Eros and thanatos in the Poem Xxx of Trilce
}

Nehemías Vega Mendieta ${ }^{1}$

\begin{abstract}
Resumen
El presente texto busca explicar la relación de Eros y Tanatos que se configura en los poemas eróticos de Trilce (1922). La investigación utilizará las ideas vertidas por la retórica cognitiva y el psicoanálisis freudiano para explicar las relaciones entre el sexo y la muerte en el poema XXX de Trilce, además se vinculará con otros poemas para establecer esta idea como un tópico común en la poesía vallejiana.
\end{abstract}

Palabras clave: eros; tanatos; Vallejo; Trilce; sexo; muerte; retórica; metáfora.

\begin{abstract}
The present text seeks to explain the relationship of Eros and Thanatos which is configured in the erotic poems of Trilce (1922). The investigation will use the ideas spelled out by the cognitive rhetoric and the Freudian psychoanalysis to explain the relationship between sex and death in the poem XXX of Trilce, in addition will be linked with other poems to establish this idea as a common topic in Vallejo's poetry.
\end{abstract}

Keywords: eros; tanatos; Vallejo; Trilce; sex; death; rhetoric; metaphor.

\section{Introducción}

El presente trabajo de investigación se centrará en la obra del poeta César Vallejo y, específicamente, abordará la relación entre Eros y Tanatos en el poema XXX de Trilce (T-XXX) y se vinculará a otros poemas de corte erótico de este y otros libros de Vallejo. Para ello, se procederá al análisis de dicho poema a partir de la retórica cognitiva y la teoría freudiana.

Para este estudio, se utilizará como marco teórico, la retórica textual cognitiva y se tomará como textos clave para el análisis Prolegómenos a una teoría general de las figuras (2000) de Stefano Arduini y Metáforas de la vida cotidiana (1995) de George Lakoff y Mark Johnson. Se utilizará las categorías vertidas por estos estudiosos, tales como campo retórico, campo figurativo y obviamente el concepto de figura que se maneja en ambos textos.

Primero, se presentará el marco teórico y se definirá el concepto de campo retórico y campo figurativo a partir de lo propuesto por Arduini; también se definirá el concepto de metáfora a partir de la concepción de Lakoff y Johnson. Luego, se mencionará los aportes críticos que algunos estudiosos han hecho sobre Trilce y se hablará de la estructura del libro. Por último, se procederá al análisis del poema XXX y de la relación que se establece con el poema "El poeta a su amada" y T-XIII.

La propuesta de este estudio es buscar la relación entre Eros y Tanatos en un poema de tema erótico de Trilce.
La edición que se manejará de Trilce será la que fue elaborada por Julio Ortega para la editorial Cátedra: Vallejo, César. Trilce. Edición de Julio Ortega. Madrid: Ediciones Cátedra, 1998.

\section{Materiales y métodos}

El material utilizado para la actual investigación ha sido documental o bibliográfico. En cuanto a la metodología, se utilizó el método hermenéutico a partir de la teoría brindada por la retórica cognitiva y mediante el análisis textual se procedió a demostrar la hipótesis planteada en la introducción.

En este apartado, se explicará el concepto de campo retórico, campo figurativo y metáfora a partir de lo planteado por Stefano Arduini, Lakoff y Johnson. Luego, se presentarán algunas propuestas críticas acerca de Trilce.

\section{Campo retórico}

La retórica es una disciplina que surgió en la antigua Grecia. En sus inicios, solo estudiaba la producción de discursos persuasivos en el arte de la oratoria, pero con el paso del tiempo se ha vinculado a otro tipo de discursos, en forma especial, con el discurso poético y literario. Los retóricos tradicionales han establecido cinco partes $\mathrm{u}$ operaciones retóricas que configuran la producción de un texto o discurso: la inventio (ideología),

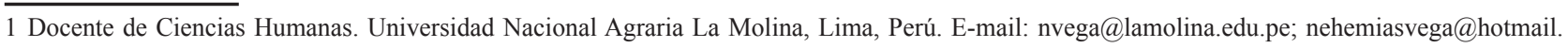
com 
la dispositio (estructura), la elocutio (estilo), la memoria y la actio (acción). Las tres primeras están directamente involucradas en el proceso de construcción del discurso retórico, pero con el transcurso del tiempo se le dio mayor importancia a la elocutio, ya que en este nivel se establece la elaboración de recursos retórico-estilísticos que permiten el carácter persuasivo de los discursos retóricos. A este grupo de estrategias estilísticas las conocemos con el nombre de figuras retóricas o literarias.

Los estudios retóricos del siglo XX se dedicaron a analizar y clasificar las figuras retóricas, debido a la preponderancia que los críticos le dieron a la elocutio, lo que originó un descuido de las otras operaciones retóricas. El estructuralismo literario rescató la tradición retórica y la adecuó a sus intereses epistemológicos, para ello tomó las propuestas de la lingüística estructuralista de Ferdinand de Saussure. Al incorporar estos aportes, Genette, Barthes, Jakobson y el Grupo Mi renovaron la retórica, por lo que sus estudios serán llamados como neorretórica. El principal campo de investigación de esta será el análisis de las estrategias elocutivas o figuras en la estructuración de discursos literarios.

El Grupo Mi o Grupo de Lieja fue el que realizó la propuesta más sofisticada y totalizadora. Ellos plantearon la existencia de la figura como recurso transgresor o representativo de un desvío del lenguaje de su llamado grado cero. Este grado cero sería la expresión reducida a sus semas esenciales.

Esta perspectiva de la figura como un desvío del lenguaje ha sido puesta en debate, a partir de propuestas que tienen una visión más amplia de la retórica al incorporar los estudios culturales. Una propuesta significativa es la del italiano Stefano Arduini, quien en su libro Prolegómenos a una teoría general de las figuras (2000), redescubre la importancia de las figuras, no solo como posibilitadoras de conocimiento, sino además como configuradoras de una realidad que es aquella que se puede conocer o construir, teniendo como modelador insoslayable al lenguaje.

Un aporte importante de Arduini es que incluye a la intellectio como una operación importante que se une a la inventio, la dispositio, la elocutio, la memoria y la actio. La operación de intellectio vincula el lenguaje con el mundo, pues es una operación "que encamina y dirige el proceso retórico estructurando el modelo de mundo compartible por orador y destinatario" (2000: 46). Además, señala que la intellectio, la memoria y la actio son operaciones no constitutivas del texto, mientras que las operaciones constitutivas son la inventio, la dispositio y la elocutio, las cuales han sido muy estudiadas por la tradición.

La propuesta de Arduini va a establecer ciertas categorías que van a ser decisivas para la configuración de su sistema teórico. Entre ellas tenemos la de hecho retórico como "acontecimiento que conduce a la producción de un texto retórico"; el texto retórico, que es el producto lingüístico. El concepto de campo retórico según Arduini es:
“(...) la vasta área de los conocimientos y de las experiencias comunicativas adquiridas por el individuo, por la sociedad y por las culturas. Es el depósito de las funciones y de los medios comunicativos formales de una cultura y, en cuanto tal, es el substrato necesario de toda comunicación. En este sentido, el Campo Retórico viene a estar constituido por la "interacción" de los hechos retóricos sea en sentido sincrónico, sea en sentido diacrónico" (2000: 47).

Por lo tanto, el campo retórico implica el conjunto de conocimientos que posee un individuo, una sociedad o una cultura. Otros conceptos importante planteado por Arduini es el campo figurativo, además se explicará la clasificación que realiza sobre las figuras retóricas.

\section{Campo figurativo}

Las figuras literarias o retóricas no fueron concebidas como simples adornos lingüísticos, ni tampoco desviaciones de la norma, pues el lenguaje desde su origen ha sido figurado y la distinción entre denotación y connotación es relativa, ni siquiera el discurso científico, que era tomado como ejemplo del grado cero de la escritura, deja de usar metáforas y muchos de sus modelos teóricos están construidos a partir de figuras retóricas, tal como señala Arduini: “(...) las figuras representan algo más profundo: unas estructuras universales de organización expresiva del pensamiento no reducibles a la simple dialéctica norma-desvío" (2000: 136). Las figuras son modalidades de pensamiento que no se quedan solo en el plano microestructural del texto, pues con las figuras se da a conocer expresivamente el mundo a partir de operaciones generales de nuestro pensamiento. Estas maneras de pensar, de ver el mundo, ha llevado a Arduini a plantear el concepto de campo figurativo.

Los campos figurativos son espacios conceptuales que permiten el conocimiento del mundo a través del lenguaje. El crítico italiano clasifica estos campos figurativos en seis: metáfora, metonimia, sinécdoque, antítesis, repetición y elipsis.

El campo figurativo de la metáfora está integrado por la catacresis, el símbolo, el emblema, la alegoría, la similitud, la personificación, la parábola y la propia metáfora. Sin duda, la metáfora ha sido una de las figuras más estudiadas y se ha dicho muchas veces que en ella opera un proceso de sustitución, en la que se coloca una cosa en lugar de otra, pero ya varios críticos se han encargado de rechazar esa idea, pues la metáfora se construye a partir de la asociación de dos ideas para crear una nueva idea, en ella se presenta una relación analógica. (...) la metáfora tiene la función de construir una imagen del mundo y por ello no es sustituible. En este sentido, crear metáforas es entonces esencial para que el discurso pueda realizarse, estas no constituyen un lastre para la lengua como la idea de sustituibilidad, con lo que lleva de inesencial consigo, puede hacer pensar, sino con su núcleo generador. Así cuando decimos de alguien que es "un zorro" suprimiendo ciertos semas del lexema y destacando otros que 
muestran algunas cualidades del zorro, construimos una imagen que nos da las coordenadas de una persona, en este caso, o de una situación en otros. Esto significa que no tendría otros medios para describir una situación si no es utilizando ciertos medios figurales: no se trata de enriquecer una expresión para hacerla más evidente o más clara: se trata de construir a través de ella una sección del mundo (2000: 84).

El campo de la metonimia se presenta en el área de la contigüidad que lo distingue de la sinécdoque. En la metonimia tampoco existe la idea de sustitución, sino una relación de contigüidad que puede ser causa-efecto, efecto-causa, materia-objeto, continente-contenido, concreto-abstracto, abstracto-concreto, signo-cosa, lo físico-lo moral, instrumento-persona, autor-obra, entre otras más.

El campo de la sinécdoque se desarrolla en el área de la inclusión y muestra la parte por el todo, el todo por la parte, el género por la especie, la especie por el género, el singular por el plural y el plural por el singular.

El campo figurativo de la antítesis refleja un modo de pensar con oposiciones. Este campo presenta las siguientes figuras: la negación, la inversión, la ironía, el oxímoron, la paradoja, el hipérbaton.

El campo figurativo de la elipsis está integrado por figuras que operan con arreglo a un criterio de fragmentación de la expresión que pude llegar a su anulación, pero la palabra o frase se esconde para mostrar: la ausencia sugiere la presencia de lo ausente. Las figuras de este campo son el silencio, la objeción, la reticencia, la perífrasis, el eufemismo y la elipsis propiamente dicha.

El campo figurativo de la repetición refleja un pensamiento obsesivo o reiterativo. Presenta las siguientes figuras: la repetición, la amplificación, la anadiplosis, el clímax, el quiasmo, la postposición, la anáfora, la epifora, el polisíndeton, la paronomasia, el poliptoto, la figura etimológica, la sinonimia, la equivocidad, el énfasis, la distinctio, la antanaclasis, la aliteración y la rima.

\section{La metáfora}

La metáfora es la figura retórica más utilizada no solo en la literatura, sino también en la vida cotidiana, pues nuestra manera de ver el mundo, de pensar y de hablar se construye a partir de metáforas. Lakoff y Johnson en su texto Metáforas de la vida cotidiana analizan y estudian esta figura y sostienen lo siguiente:

(sangría de media pulgada para toda esta cita) Para la mayoría de la gente, la metáfora es un recurso de la imaginación poética y los ademanes retóricos, una cuestión de lenguaje extraordinario más que ordinario. Es más, la metáfora se contempla característicamente como un rasgo solo del lenguaje, cosa de palabras más que de pensamiento o acción. Por esta razón, la mayoría de la gente piensa que pueden arreglárselas perfectamente sin metáforas. Nosotros hemos llegado a la conclusión de que la metáfora, por el contrario, impregna la vida cotidiana, no solamente el lenguaje, sino también el pensamiento y la acción. Nuestro sistema conceptual ordinario, en términos del cual pensamos y actuamos, es fundamentalmente de naturaleza metafórica (1995).

La metáfora, más que una figura del lenguaje, es un proceso constituyente del pensamiento humano, nuestro sistema conceptual ordinario es de naturaleza metafórica. Lakoff y Johnson clasifican las metáforas en tres tipos: estructurales, orientativas y ontológicas. Las metáforas estructurales se presentan en los casos en los cuales un concepto está estructurado metafóricamente a partir de otro (El tiempo es oro). Las metáforas orientativas tienen como base la orientación espacial arriba-abajo, dentrofuera, delante-detrás, profundo-superficial, centroperiferia o cerca-lejos; estas metáforas se originan a partir de la forma particular de nuestro cuerpo y su relación con el medio físico. Las metáforas ontológicas son aquellas en las que se consideran a los acontecimientos, actividades, emociones e ideas como entidades o sustancias (La mente es una máquina).

\section{Recepción crítica de Trilce}

Luis Monguió, en su libro César Vallejo. Vida y obra (1952), menciona su asombro por el cambio radical que experimentó Vallejo en tan pocos años, de un libro como Los heraldos negros (1918), en el cual la poética modernista imperaba claramente, a un poemario como Trilce (1922) que, en palabras del crítico, fue un "acto de rebelión poética" (1952), un libro que es la expresión peruana de la nueva visión de la vida y del mundo tras la etapa de posguerra que se vivía en Europa. El crítico señala que entre los años 1918 y 1922, Vallejo pasa por experiencias críticas que trasladará luego a su poesía: "Y es indudable que su literatura es esencialmente autobiográfica, en el sentido de autobiografía espiritual." (1952). Señala además que en Trilce hay elementos técnicos que coinciden con los movimientos europeos y americanos de vanguardia, que a diferencia de ellos no presenta un arte deshumanizado, pues Vallejo muestra en este libro un tono netamente humano; este humanismo tiene como base la propia historia del hombre Vallejo, pues los poemas de su segundo poemario parten siempre de una experiencia del poeta trujillano. La fusión de los elementos técnicos y del vitalismo de Trilce haría aparentemente difícil la lectura del libro, pero esto no se da si se lee el texto desde la propuesta estética del autor.

Conrespectoalatécnica, Monguiórealizauna comparación entre la estructura de Los heraldos negros y Trilce e indica que el primer poemario presenta una agrupación de los poemas en torno a un tema, que no aparece en Trilce, pues los poemas de este libro están presentados como una serie única ininterrumpida, caracterizados por la ausencia de títulos y la sola numeración en romanos que demuestran la libertad creativa del autor: “(...) cada uno de ellos debe constituir en la mente del poeta una unidad subsistente por sí misma y en sí misma; cada uno de ellos ha de ser también para el lector una experiencia poética, una independiente." (1952). Trilce presenta una forma radical en el uso del verso, pues se libera de la rima 
y la métrica; esto es una muestra de que Vallejo sigue una retórica propia: "En la mayoría de ellos sigue el poeta los dictados de su retórica interior, del ritmo imaginístico, del ritmo intelectual, o del ritmo emocional del poema." (1952). Destaca también la manera como ha creado Vallejo los poemas en Trilce de la misma manera como Picasso ha compuesto sus cuadros, pues como ya se señaló, Vallejo toma como base para su poesía su experiencia personal, una circunstancia real de la que ha ido eliminando progresivamente, con una intención estética, lo episódico, lo pintoresco y lo digresivo para conseguir un poema estilizado. Es por ello que en Trilce hay una intensa carga emocional -señala Monguió- que ha sido motivada por hechos que afectaron al poeta, tales como la muerte de la madre, el regreso a Trujillo, su estancia en la cárcel, el cambio de vida en Lima. El investigador plantea que el poeta es un médium que expresa sus estados internos a través de su poesía y eso es lo que hace Vallejo en Trilce, pero lleva esto hasta sus límites:

Trilce marca en la vida poética de su autor la hora de su absoluta rebelión expresiva. Vallejo, en trance de poesía, expresa sus sentimientos de orfandad, de dolor, de desolación, de la injusticia del mundo, dejando que sus emociones dicten libremente palabras, imágenes, metáforas, asociaciones que se ordenan según un dinamismo que les es intrínseco sobre la página en blanco en que el poeta es un médium de su poema. Pero un médium controlador, que debe, puede, sabe distinguir entre libertad y caos (1952).

Además, el crítico sostiene que Trilce es un símbolo de protesta contra el mundo que ha hecho sufrir al poeta y se presenta en él una actitud filosófica negativa. Cada poema manifiesta esa protesta y esa libertad, es por ello que cada poema presenta una forma particular que lo distingue de otros poemas. Por ello, el segundo poemario de Vallejo es un libro que se agota a sí mismo y a su autor, "es un libro de apertura y de clausura". Después de ello, el autor buscará una solución a su infelicidad, al dolor de vivir. Para Monguió, Trilce es un acto de libertad y rebelión poética que manifiesta las vivencias penosas de Vallejo, pero que han sido despojadas de su anécdota y cotidianidad para ser sintetizadas y estilizadas en un lenguaje poético novedoso que lo hace universal.

Marco Martos y Elsa Villanueva, en el texto Las palabras de Trilce (1989), realizan un estudio para determinar el significado de los vocablos del poemario, además de ello presentan una pequeña interpretación de cada poema a partir de los significados precisados. Los autores también señalan algunos rezagos del modernismo en el libro, que se muestran en la estructura formal de algunos poemas y también en palabras y frases de cuño modernista. Con respecto a la vanguardia y sus rasgos en el libro, mencionan lo siguiente:

Trilce presenta coincidencias a la vez que diferencias con la vanguardia. Tienen en común: el uso de los números, de las mayúsculas, la supresión ocasional de nexos lógicos, la distribución arbitraria de los versos y el uso de la onomatopeya. Como notas contrarias al espíritu de la vanguardia se dan en Trilce: el tema autobiográfico, la anécdota y rezagos métricos en algunos poemas de clara raigambre modernista que fueron originalmente sonetos (1989).

Vallejo no fue un poeta que siguió los postulados de las distintas escuelas vanguardistas, no fue un subordinado de la poesía europea, sino que fue un intérprete de su circunstancia en palabras de los autores. Mientras otros jugaban con las palabras, Vallejo peleaba con ellas para que dijeran lo que usualmente no dicen. Lo importante del texto de Martos y Villanueva es la clasificación temática y formal de los poemas. En la clasificación temática, los autores plantean el tema amoroso (35 poemas), el tema existencial (23 poemas), el tema del hogar ( 7 poemas), el tema de la cárcel (6 poemas) y el tema sobre la reflexión estética (6 poemas). Los autores, al observar el predominio del tema amoroso, sostienen que "Trilce es temáticamente un poemario de amor" (Martos y Villanueva, 1989) que se vincula a libros como Veinte poemas de amor y una canción desesperada de Neruda (1924) y La voz a ti debida de Salinas (1933), en los cuales se realiza una exploración de la afectividad amorosa. Con respecto a la clasificación formal, los autores mencionan cuatro tipos de poemas según la forma de composición formal: la primera etapa es de tránsito lexical (15 poemas); la segunda es de hermetismo lexical (13 poemas); la tercera es de claridad lexical (45 poemas) y la cuarta está integrada por poemas escritos en prosa (4 poemas). En los poemas de tránsito lexical, Vallejo va de una claridad modernista, con un lenguaje sencillo, a un hermetismo lexical propio de la vanguardia. Los poemas de hermetismo lexical presentan un oscurecimiento poético mediante un vocabulario rebuscado. Los de la tercera etapa de claridad lexical se caracterizan por el uso de un lenguaje sencillo, pero la complejidad de estos poemas radica en su fuerte carga simbólica. En los poemas escritos en prosa, deja de lado las formas poéticas tradicionales y vanguardistas, mientras que el lenguaje transita desde la claridad hasta el hermetismo. A manera de conclusión, Martos y Villanueva plantean que la organización laberíntica del libro muestra el verdadero caos de la intimidad del poeta y como hipótesis sostiene que esto se debe a la voluntad de no entregar de manera fácil la intimidad.

Roberto Fernández Retamar, en su artículo "Para leer a Vallejo", señala la importancia de Trilce en el contexto literario, equiparando la obra de nuestro vate con el Ulises de Joyce y La tierra baldía de Eliot (publicadas ambas en 1922), aunque las situaciones y espacios hayan sido distintos. Sorprende al crítico que un libro como Trilce haya sido creado en una ciudad como Lima, lejos de los problemas que aquejaban Europa, ya que estos fueron el detonante para el surgimiento de los ismos de vanguardia, los cuales mostraban su rebeldía contra los terribles sucesos que ocurrían en el viejo mundo. La creación de Trilce, en cambio, obedece a una rebeldía personal motivada por experiencias críticas del autor. 
Roberto Paoli, en su estudio Mapas anatómicos de César Vallejo (1981), plantea que Trilce es “quizás el libro más original y fecundo de la vanguardia posbélica" (p. 9). El crítico italiano señala que Trilce muestra un alejamiento expresivo con respecto a Los heraldos negros y se presenta como un libro más compacto y homogéneo, a diferencia del primero. Esto se infiere de los datos obtenidos de las versiones iniciales de los poemas, pues Trilce debió pasar por dos fases en su composición. En la primera etapa, el poeta siguió los criterios de composición de Los heraldos negros, pero luego, a partir de las lecturas de revistas del ultraísmo español, recibe la influencia de la vanguardia y conoce las nuevas formas poéticas, a partir de las cuales realiza una interpretación personal. Aunque se habla de cierta violencia en el cambio de un poemario a otro, el investigador menciona que ya en Los heraldos negros se anuncia la evolución que habría en Trilce, libro con el cual alcanza un acento propio, aprende a dominar las influencias y sigue un camino propio.

En conclusión, se puede observar que la crítica mencionada plantea el carácter innovador de Trilce dentro de la poesía peruana y mundial, a partir de la forma y el contenido de los poemas.

\section{Resultados y discusión}

Tomando como punto de partida la teoría explicada y la crítica sobre Trilce, se procederá al análisis de Trilce XXX (T-XXX), poema en que el hablante lírico une las pulsiones del amor y la muerte a partir del acto sexual.

\section{Análisis textual: Figuras retóricas, interlocutores y} cosmovisión en T-XXX

Trilce es un poemario que presenta un marcado hermetismo que puede constituir un obstáculo para el que quiera desentrañar el sentido de los poemas que lo conforman, por ello, representan un reto para cualquier estudioso de la obra de Vallejo. En este apartado, se analizará el poema XXX de Trilce estudiando las figuras retóricas para poder así conocer la cosmovisión vallejiana que subyace en el poema. Primero, se realizará una segmentación textual del texto y se colocará un título tentativo a los segmentos para conocer la progresión temática del poema. Luego, se procederá a un análisis de las figuras retóricas a partir de los campos figurativos planteados por Stefano Arduini. En tercer lugar, se estudiará los interlocutores que se configuran en el poema a través de las categorías de locutor y alocutario. Tras ello se desarrollará la visión del mundo que presenta el poema a partir de la relación de Eros y Tanatos según las ideas vertidas por Freud. Y, por último, se vinculará a otros poemas del mismo poeta para ver la intertextualidad entre un poema y otro. A continuación, se incluye el poema objeto de estudio, Trilce XXX, para una mejor comprensión del análisis.

\section{XXX}

Quemadura del segundo

en toda la tierna carnecilla del deseo,

picadura de ají vagoroso, a las dos de la tarde inmoral.

Guante de los bordes borde a borde.

Olorosa verdad tocada en vivo, al conectar

la antena del sexo

con lo que estamos siendo sin saberlo.

Lavaza de máxima ablución.

Calderas viajeras

que se chocan y salpican de fresca sombra

unánime, el color, la fracción, la dura vida,

la dura vida eterna.

No temamos. La muerte es así.

El sexo sangre de la amada que se queja

dulzorada, de portar tánto

por tan punto ridículo.

$\mathrm{Y}$ el circuito

entre nuestro pobre día y la noche grande, a las dos de la tarde inmoral.

(Vallejo 1998).

\section{Segmentación textual}

T-XXX está integrado por veinte versos distribuidos en dos cuartetos y dos sextetos. Se ha dividido el poema en tres segmentos para un mejor análisis de la progresión temática. El primer segmento incluye a las dos primeras estrofas, del verso 1 al 8 , y el título tentativo que se le ha puesto es "El encuentro sexual y el desconocimiento de la identidad". El segundo segmento correspondería a la tercera estrofa, del verso 9 al 14, y el título sugerido es "El sexo como limpieza y su relación con la muerte". El tercer segmento correspondería a la cuarta estrofa, del verso 15 al 20, y el título planteado es "La queja de la amada y la conciencia cíclica del tiempo".

\section{Figuras literarias}

En el poema, el campo figurativo predominante es el de la metáfora; en efecto, encontramos dos de ellas, una que hace referencia a los genitales femeninos "tierna carnecilla del deseo" y otra que alude a los genitales masculinos "picadura de ají vagoroso". En esta segunda metáfora, Vallejo juega con la ambigüedad de la palabra picadura que puede aludir tanto a la acción de picar como de punzar o hincar, así como a la idea de irritación del paladar causada por "ciertas cosas excitantes" como son, justamente, el pimiento o el ají, lo cual es una acepción de la palabra "picar" que hallamos en el Diccionario de la Real Academia Española (DRAE).

Asimismo, la palabra ají es de origen taíno, lengua precolombina, y en el poema se utiliza para aludir al órgano sexual masculino. Igualmente en el verso 7, aparece la metáfora "la antena del sexo" que nuevamente 
hace referencia a los genitales masculinos. En el verso 10, se halla la metáfora "calderas viajeras" que alude a los cuerpos de los amantes según el contexto del poema; la metáfora se construye a partir de la idea de que nuestros cuerpos son recipientes como las calderas. Otra metáfora es "el sexo sangre de la amada", que hace referencia a los genitales femeninos; el hablante lírico sugiere que son como una herida, aunque la presencia del lexema sangre haría pensar en la menstruación o la pérdida de la virginidad; esta última idea se refuerza con la palabra "queja" que prosigue a la metáfora. La metáfora "olorosa verdad tocada en vivo" también alude a los genitales femeninos que son tocados por "la antena del sexo".

El otro campo figurativo importante es el de la antítesis. Hallamos, por ejemplo, la antítesis en el verso 9, "lavaza de máxima ablución", que opone las ideas de suciedad y limpieza, pues la lavaza es el agua sucia que queda de lo que se lavó en ella y la ablución es la acción de lavar, es decir, la limpieza. En los versos 16 y 17, también se presenta una antítesis: "de portar tánto / por tan punto ridículo", en la cual se oponen el tamaño, en este caso de los genitales. En el verso 19, aparece la antítesis "nuestro pobre día y la noche grande" que implica una conciencia angustiante del tiempo, además el día sugiere la idea de vida y la noche la de la muerte. La vida es corta - pobre día- y la muerte es definitiva y absoluta - noche grande-, aunque forman parte de un circuito. Esta antítesis, además, se relaciona con la creencia del yo poético de que el acto sexual debe realizarse durante la noche, bajo la protección de la oscuridad, y por lo tanto, es inmoral realizarlo durante el día "a las dos de la tarde inmoral". La noche es magnificada, ya que es propicia para el acto sexual; en cambio, el día es menospreciado, ya que no es el momento ideal para la realización del encuentro físico de los amantes.

El campo figurativo de la metonimia se manifiesta en el verso cinco, a través de la metonimia continentecontenido, "guante de los bordes borde a borde"; el guante hace alusión a la mano y en el poema sugieren la unión de los dos genitales en el acto sexual: el guante (continente, lo femenino) que hace clara referencia a la vagina y la mano (contenido, lo masculino) que alude al falo. Monique Lemaitre interpreta este verso de manera directa, para ella "hacen alusión ambos al prepucio masculino y a los labios del sexo femenino que son envolturas protectoras 'guantes"' (2001).

El campo figurativo de la repetición se manifiesta en la anáfora "a las dos de la tarde inmoral" que se presenta en los versos 4 y 20. El tiempo en Vallejo es un tópico central y en el poema adquiere vital importancia esta conciencia del tiempo, pues a través del instante del acto sexual se hace alusión a lo eterno, a la inmensidad de la muerte. El tiempo específico, las dos de tarde, es significativo, pues ese número remite a par que, a su vez, remite a pareja. El adjetivo inmoral connota cierta carga de culpa.

Es interesante también destacar en el poema una retórica de los sentidos, de lo sensorial, que se une a lo metafísico.
Los cinco sentidos se presentan en el poema. El tacto se encuentra en la "quemadura del segundo", "olorosa verdad tocada en vivo" y "guantes de los bordes". El olfato es aludido a partir de "olorosa verdad". El gusto se manifiesta con "picadura de ají vagoroso" y "dulzorada". La vista a partir de las imágenes del poema, pero también con las alusiones cromáticas: "el color", "el sexo sangre". Y el sentido del oído se hace presente con "la queja dulzorada de la amada".

\section{Interlocutores}

En el poema, se configura un locutor en plural, un nosotros implícito en el verbo del verso 14 ("No temamos"), aunque realmente es un solo locutor que habla por el grupo, en este caso la pareja. Este hablante lírico realiza un monólogo, pues no se configura un alocutario, es decir, no está representado por ningún deíctico u otra marca textual. Pero, al ser un "nosotros", la voz poética que habla puede dirigirse a los otros que se incluyen dentro de su grupo. Este locutor representado habla sobre el acto sexual y su trascendencia del instante y lo sensorial a lo metafísico.

\section{Cosmovisión}

Las figuras retóricas configuran una manera de ver el mundo, es decir, una cosmovisión; en el poema, a partir del acto sexual físico y sensorial de carácter efímero, el autor construye la angustia por la muerte. El acto sexual, que implica vida y reproducción, es amenazado por la conciencia de la muerte. El poema sugiere una historia, la del encuentro entre dos amantes en un tiempo inadecuado para el acto sexual, las dos de la tarde, momento que es considerado inmoral y que implica un sentimiento de culpa, pues atenta contra las costumbres y valores de la época.

La segunda estrofa plantea que el deseo sexual se impone a los amantes y es más fuerte, por ello, se produce el acto amatorio mediante un abandono de la conciencia, tal como sugiere el verso 8: "con lo que estamos siendo sin saberlo". De alguna manera, el locutor plantea que la cópula sexual produce la pérdida de identidad personal, esa sensación de no existencia parecida a la de la muerte. Hay un desconocimiento de su identidad en el acto sexual, un abandono del yo, tras la llegada del orgasmo.

Luego, en la tercera estrofa, se hace referencia a la idea de suciedad y limpieza a través del sexo; a partir de esta antítesis se liga el sexo con lo sucio, lo pecaminoso, pero también, a la vez, con la limpieza, la purificación. Las calderas viajeras se pueden interpretar como los genitales masculino y femenino que luego de estar separados se unen, se chocan y salpican para llegar al paroxismo sexual, ese momento en el cual se produce el abandono del yo, la pérdida de conciencia, que Bataille llama la "pequeña muerte", es decir, el orgasmo; este es una afirmación de la vida, pero también un contacto con la muerte. Así, en el poema, se produce la conciencia de la relación entre las dos pulsiones de Eros y Tanatos a partir de la reflexión del instante del éxtasis sexual. 
Freud, en su libro Más allá del instinto del placer (1920), considera que existen dos fuerzas en todo organismo biológico, pulsiones que determinan el curso de sus actividades y deseos: el instinto de vida o Eros y el instinto de muerte o Tanatos. Eros se caracteriza por la disposición del sujeto para formar unidades siempre mayores; esta pulsión es siempre deseo de unión o atracción y, por ejemplo, se manifiesta en el amor, la actividad sexual, la reproducción y el afán por mantener la propia unidad física y psíquica. Tanatos, en cambio, se manifiesta como una disposición a la repulsión, a la disgregación, a la ruptura de la unidad entre sus distintas partes para volver al estado desorganizado y, en último término, a lo inanimado, es decir, la muerte. Tanatos es siempre un deseo de pasividad, de separación y de disolución de unidades. Las manifestaciones patológicas de este instinto son el sadismo, el masoquismo, el suicidio.

En el poema, el acto sexual, el deseo de unión con la pareja, está relacionado con la idea de la muerte, de separación o disolución del yo, ya que en el instante de plenitud sexual se produce la pérdida de la conciencia, un abandono del yo, incluso del nosotros de la pareja, pues es un momento de desapego del ser, semejante a la muerte. Esto produce una angustia metafísica en el locutor o yo poético; esta idea se manifiesta en los versos: "unánime, el color, la fracción, la dura vida, / la dura vida eterna. / No temamos. La muerte es así". Según el poema, en ese instante del clímax se juntan de manera unánime la vida y la muerte. Se presenta la conciencia de que la vida es dura debido a su brevedad, por ello, se manifiesta la angustia ante la muerte que lleva a la aceptación de esta como parte del ciclo vital.

La cuarta estrofa plantea que el encuentro sexual es un descubrimiento para ambos amantes, pues la sangre en el sexo de la amada sugiere que ha sido desvirgada, ya que ha sido doloroso, pero dulce a la vez: "El sexo sangre de la amada que se queja / dulzorada, de portar tánto / por tan punto ridículo". Esta primera vez del orgasmo ha hecho tomar conciencia a los amantes del circuito de la vida, la vida es corta y pobre como el día y la noche es grande y definitiva como la muerte.

T-XXX es un poema que puede ser calificado, a la vez, como erótico y metafísico, pues a partir del acto físico de la cópula, el hablante lírico reflexiona sobre la identidad del ser y la angustia por la conciencia de la muerte. Este tópico de la unión indisoluble entre sexo y muerte es constante en la poesía vallejiana y se puede hallar en otros poemas de Trilce como T-IX y T-XIII, e incluso en Los heraldos negros, pero a diferencia de este, en Trilce hay una visión de un erotismo libre y descarnado, despojado de idealismos románticos que todavía presentaba el primer poemario.

\section{Intertextualidad}

Otro poema de Vallejo que aborda esta relación de Eros y Tanatos, entre amor y muerte, es "El poeta a su amada", pero a diferencia de T-XXX, en dicho poema el erotismo es sugerido y casi inocente, además en él se encuentran las ideas de vida y muerte junto a referencias cristianas que no hallamos en los poemas eróticos de Trilce. La muerte no es vista como angustiante, sino como algo benigno y aceptable. Se percibe todavía una concepción romántica del amor, que transgrede la muerte; esta es una postura idealista. En T-XXX, se presenta una superación de esta concepción idealista y romántica, pues el amor es más físico sin dejar de lado la subjetividad y la reflexión, pero además se observa que queda un cierto tono de angustia metafísica o de insatisfacción, e incluso de culpa.

T-XXX también se relaciona directamente con Trilce XIII. En ambos poemas, el acto sexual es visto de manera predominantemente física, aislado de los sentimientos, tal como sugiere el verso "simplificado el corazón, pienso en tu sexo" o en "Y muere un sentimiento antiguo/ degenerado en seso" de T-XIII. El locutor deja de lado los sentimientos en el momento del acto sexual. Además, el sexo femenino se configura como surco prolífico a través de la metáfora: "Pienso en tu sexo, surco más prolífico/ y armonioso que el vientre de la Sombra". El sexo femenino es surco prolífico, pues ambos tienen la función reproductora. Luego, el locutor une esta idea a la "Muerte que también concibe y pare" para hacer referencia al ciclo vital, pues se sugiere la idea de que la muerte no es el fin de la vida, sino una parte de ella. Nuevamente, se observa aquí la unión de Eros y Tanatos que aparece en el poema T-XXX, además la muerte es asumida de manera negativa con cierta angustia. Luego, el pensamiento se traslada al bruto que puede gozar con libertad. En los últimos versos, se produce la relación del sexo con el lenguaje o con el silencio que también es una forma de lenguaje. "Oh, escándalo de miel de los crepúsculos. / Oh estruendo mudo. / ¡Odumodneurtse!”. Estas líneas hacen referencia a la llegada del orgasmo, tras el ruido del encuentro sexual, se produce el aturdimiento de la conciencia y el silencio que sobreviene y que en el poema T-XIII se observa a través de la inversión de "estruendo mudo" por "odumodneurtse".

Por lo expuesto, vemos una ligazón temática entre estos poemas, la relación entre Eros y Tanatos y también el predominio de lo físico en el acto sexual.

\section{Conclusiones}

A partir del análisis del poema analizado encontramos que Vallejo, en Trilce, expone una concepción más física o corporal del sexo y en sí del amor; se percibe un erotismo libre desvinculado de lo sentimental. Este ya no se presenta de manera idealista y romántica, y con cierta carga de culpa como aparece en Los heraldos negros. El sexo y el amor en Trilce son de carácter vital, una manera de afirmación de la vida. Aunque hallamos cierta angustia o insatisfacción al final de T-XXX y T-XIII. A la vez, une las ideas de Eros y Tanatos, pulsiones o instintos que se ligan en los amantes en el momento de la cópula sexual. Esta ligazón se presenta en los poemas IX, XIII y XXX. La relación del sexo con la muerte es una constante en los poemas de amor y erotismo en este poemario vanguardista. 
Los campos figurativos que más utiliza Vallejo en los poemas analizados son los de la repetición, la metáfora y la antítesis. Estos configuran una cosmovisión sobre el tema del erotismo en los cuales se unen el sexo y la muerte.

\section{Literatura citada}

Arduini, S. 2000. Prolegómenos a una teoría general de las figuras. Murcia, España: Universidad de Murcia, Servicio de Publicaciones.

Bataille, G. 1997. El erotismo. Madrid, España: Tusquets Editores.

Fernández, R. 2007. Antología personal. México: Siglo XXI Editores.

Freud, Sigmund. 1948. Obras completas (Tomo I). Madrid, España: Editorial Biblioteca Nueva.

Lakoff, G. y Johnson, M. 1995. Metáforas de la vida cotidiana. Madrid, España: Ediciones Cátedra S. A.

Lemaitre, M.J. 2001. Viaje a Trilce. México: Plaza y Valdés Editores.

Martos, M. y Villanueva, E. 1989. Las palabras de Trilce. Lima, Perú: Seglusa Editores.

Monguió, L. 1952. César Vallejo. Vida y obra. Lima, Perú: Editora Perú Nuevo.

Paoli, R. 1981. Mapas anatómicos de César Vallejo. Florencia, Italia: Casa Editrice D'Anna.

Vallejo, C. 1996. Obra poética. Edición de Américo Ferrari. Lima, Perú: ALLCA XX.

Vallejo, C. 1998. Trilce. Edición de Julio Ortega. Madrid, España: Ediciones Cátedra S. A. 